\title{
Numerical Analysis of Eccentrically Loaded Cold-Formed Plain Channel Columns
}

\author{
A. P. Nivethitha, G. Vani, and P. Jayabalan \\ National Institute of Technology, Tiruchirappalli 620015, India \\ Correspondence should be addressed to A. P. Nivethitha; nivethitha.ap@gmail.com
}

Received 20 February 2014; Revised 20 May 2014; Accepted 26 May 2014; Published 24 June 2014

Academic Editor: Lucio Nobile

Copyright (C) 2014 A. P. Nivethitha et al. This is an open access article distributed under the Creative Commons Attribution License, which permits unrestricted use, distribution, and reproduction in any medium, provided the original work is properly cited.

Finite element analysis of pinned cold-formed plain channel columns of different width-to-thickness ratios is presented in this paper. The study is focused not only on axially loaded columns, but also on eccentrically loaded columns. The general purpose finite element software ABAQUS 6.12 was used, and the force controlled loading was adopted. Geometric and material nonlinearities were incorporated in the finite element model. The ultimate loads are compared with the direct strength method (DSM) for axially loaded columns. Also, a parametric study is done by varying the length of the column and width of the unstiffened element. It is observed that the results correlate better with the DSM values for columns having unstiffened elements of lower $b_{f} / t$ ratios. The change in ultimate load is studied only in ABAQUS, as the position of load moves towards the free edge and the supported edge of the unstiffened element. A parametric study is done by varying the nonuniform compression factor for the columns. It is observed that the ultimate load increases as the position of load moves towards the supported edge and it is influenced by the $b_{f} / t$ ratio of the unstiffened element.

\section{Introduction}

There are two main categories of steel structural members, namely, hot-rolled and cold-formed sections. Hot-rolled sections are quite familiar. Cold-formed steel sections have been used in car bodies, railway coaches, equipment, transmission towers, and so forth. Their application as structural members is the prime interest of ongoing research. Coldformed members are generally known for their thin elements, buckling behaviour, and postbuckling strength. They have high strength-to-weight ratio and a thickness as small as $0.5 \mathrm{~mm}$ can be achieved. In the cold-formed family, many configurations such as angle, channel, I, Z, sigma, T, and tubes can be produced. Some of them are entirely composed of stiffened elements or unstiffened elements or a combination of both. Owing to the existence of such elements, each section behaves in its own way. This paper has focused on the behaviour of plain channel sections. Plain channel members are generally used as wall studs, rafters, truss members, and floor joists. In North America, channels have been categorised as S members which are lipped channels, most often used for wall studs, floor joists, and ceiling or roof rafters, $\mathrm{T}$ members which are unlipped channels, used for top and bottom plates (tracks) in walls and rim joists in floor systems, and $\mathrm{U}$ members which are again unlipped channels but have a smaller depth than tracks and are used to brace members, as well as for ceiling support systems.

Kalyanaraman and Ramakrishna [1]developed a procedure for calculating the buckling and postbuckling strength of stiffened elements subjected to nonuniform compression. An effective width equation was proposed similar to that given by Winter for uniformly compressed elements, but it was applicable to the entire range of stress gradient starting from uniform compression to uniform bending. The results were compared with those obtained from experiments conducted on nonuniformly compressed webs in beams and eccentrically loaded columns. Kalyanaraman and Jayabalan [2] presented an analytical procedure for calculating the local buckling strength based on which the equations were proposed for the local buckling stress of nonuniformly compressed stiffened and unstiffened elements. The results were compared with experimental values. El-Sheikh et al. [3] described the behavior of stiffened and unstiffened channel members. The section properties and the effect of the use 
of stiffeners were discussed, and structural performance was assessed according to British Standard Specifications BS5950. A wider parametric study was made for channel members with various aspect ratios, stiffeners' sizes, and slenderness ratios. The results revealed how the members could be profiled to obtain the optimum performance in various applications.

Schafer et al. [4] provided an overview of computational modelling, both elastic buckling and nonlinear collapse analysis, for cold-formed steel members. Tools like CUFSM and ABAQUS were used, and issues such as how to fully compare finite strip and finite element solutions were elaborated with examples. The importance of imperfections, residual stresses, material modelling, boundary conditions, element choice, element discretization, and solution controls in collapse modelling of cold-formed steel were also highlighted.

Young and Yan $[5,6]$ developed nonlinear finite element models for lipped and plain channel sections, wherein geometrical and material nonlinearities were included and verified against fixed ended channel column tests. An extensive parametric study of cross-section geometries was made. The column strengths obtained were compared to the design column strengths calculated using the American, Australian/New Zealand, and European specifications for coldformed steel structures. It was shown that the design column strengths calculated from the three specifications were generally conservative. Young and Rasmussen [7] presented an experimental investigation into the plain and lipped channel sections for both fixed ended and pin ended conditions. For plain channel columns, the difference in strength caused by the effect of local buckling was the greatest at short and intermediate lengths where the strength is influenced by local buckling. Nguyen and Kim [8] studied the buckling of thinwalled composite columns in hat sections and lipped channel sections reinforced with web stiffener. The columns were composed of symmetric angle-ply laminates. The finite element method was used to investigate the buckling behavior of the columns. Rigid body constraints were applied at the ends through reference nodes and a compressive force was applied to it. Bifurcation analyses were carried out to obtain the buckling load and mode shapes of the columns. Loaddeflection analyses were performed to study the postbuckling behavior of the columns.

Wang et al. [9] studied cold-formed steel columns with three different sections and eleven different eccentricities under eccentric compression loading by using ANSYS. It was shown that the maximum of ultimate load-carrying capacity appeared when effective eccentricity was $0 \mathrm{~mm}$ and decreased with the increase of the value of effective eccentricity. Web stiffening could improve load-carrying capacity when the eccentricity was near the web side.

Miller and Pekoz [10] studied the effects of load eccentricity on cold-formed lipped channel sections through experiments on long columns. The effects of perforations on the web were also studied. It was concluded that the axial strengths of the columns were sensitive to an eccentricity as small as $2.5 \mathrm{~mm}$. Conservative strength predictions were obtained with AISI predictions, including the load eccentricity effects and perforations modelled using unstiffened strip method.
Rhodes et al. [11] performed a series of compression tests on cold-formed stainless steel lipped channel columns. The cross-section dimensions, the column length, and the eccentricity of the load were varied and the results obtained were compared with those obtained from the relevant design specifications in America and in Europe. It was concluded that Eurocode provisions were accurate for concentrically loaded fully effective sections and conservative for eccentrically loaded columns. For concentrically loaded columns, the design codes were accurate in their predictions of the buckling loads for all but the lowest slenderness ratios examined. In this range, the ASCE predictions were more conservative than the Eurocode. Dejin and Shaofan [12] performed numerical analysis on eccentrically loaded singly symmetric open section columns. A simple method was proposed through which torsional-flexural buckling loads could be predicted very close to the test values. An empirical relation to determine the torsional-flexural buckling load was developed based on a parametric study on hat sections. But it was too conservative for other open sections.

Schafer [13] provided a review of the direct strength method (DSM) of cold-formed steel design. The equations for the design of columns and beams were provided in an excerpt from the North American Specification. A brief comparison with effective width method was provided. Current and ongoing research to extend the DSM was reviewed and references were provided. Schafer and Adany [14] showed the derivation of conventional finite strip method (FSM) analysis identical to that employed in CUFSM, from the first principals. An example of a lipped channel was provided for basic understanding. Thus, it was shown that constrained finite strip method ( $\mathrm{cFSM}$ ) combined with conventional FSM provides a powerful tool for understanding the cross-section stability.

Thus, it is clear that most of the papers are focused on the behaviour of cold-formed sections subjected to pure compression. Only limited researches have been made on sections subjected to nonuniform compression. Though earlier studies are made on axially loaded columns, achieving such a condition in reality becomes an ideal case. Nonuniform compression may result due to misalignment of columns, eccentricity of loading, or webs of beams subjected to moments. Hence, the objective of the present study is to develop finite element models for both axially loaded and eccentrically loaded columns and carry out parametric studies by varying the effective length, flat width ratio of unstiffened element, and nonuniform compression factor. DSM equations are also applied and results are compared with FEM results for axially loaded columns only. Determining the nominal strength for eccentrically loaded columns using DSM is beyond the scope of this paper.

\section{Finite Element Modelling}

2.1. General. Finite element software ABAQUS version 6.12 was used for modelling the cold-formed steel channel columns. The section dimensions were taken from the thesis by Jayabalan [15]. The rounded corners were also modelled. 


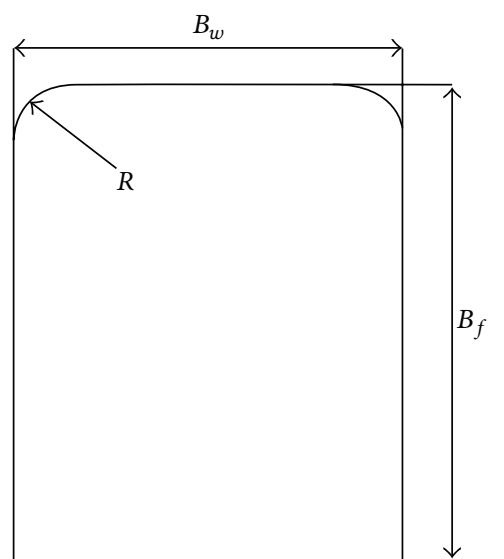

FIGURE 1: Section parameters for plain channel.

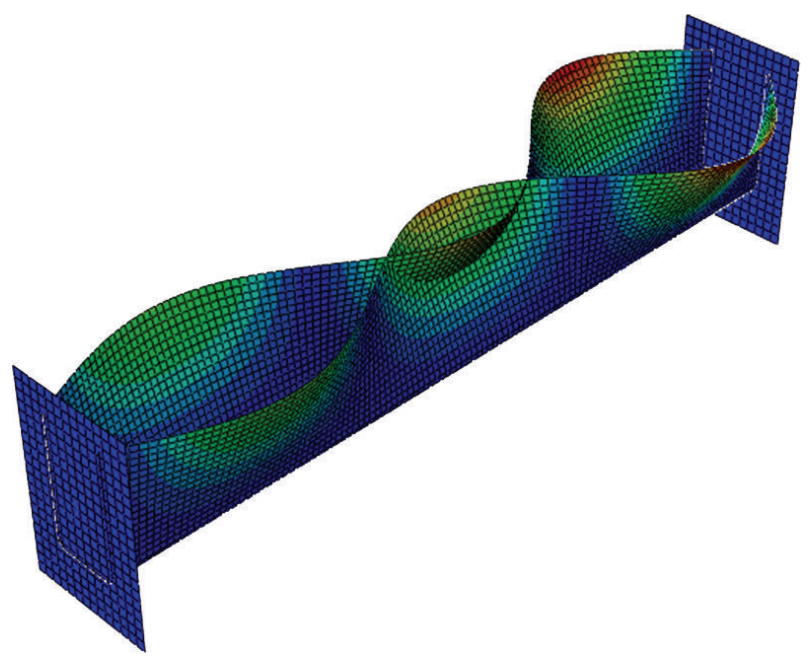

FIGURE 2: First buckling mode (local buckling) of column $\mathrm{Cl}$ of effective length $600 \mathrm{~mm}$.

TABLE 1: Cross-section dimensions for plain channel.

\begin{tabular}{lcccccc}
\hline Column number & $\begin{array}{c}B_{f} \\
(\mathrm{~mm})\end{array}$ & $\begin{array}{c}B_{w} \\
(\mathrm{~mm})\end{array}$ & $\begin{array}{c}R \\
(\mathrm{~mm})\end{array}$ & $\begin{array}{c}t \\
(\mathrm{~mm})\end{array}$ & $b_{f} / t$ & $b_{w} / t$ \\
\hline $\mathrm{C} 1$ & 96.80 & 50.00 & 6.00 & 1.94 & 45.8 & 17.59 \\
$\mathrm{C} 2$ & 120.30 & 56.80 & 6.00 & 1.73 & 65.07 & 23.90 \\
$\mathrm{C} 3$ & 59.40 & 61.00 & 5.50 & 1.73 & 30.16 & 26.90 \\
$\mathrm{C} 4$ & 184.40 & 53.10 & 6.50 & 2.09 & 84.12 & 17.19 \\
\hline
\end{tabular}

For the transfer of load, rigid plates were also modelled at the top and bottom. The section parameters defined in Table 1 are shown in Figure 1.

Initially, an eigenvalue buckling analysis was done to establish the buckling modes. In the next stage, a nonlinear analysis was performed using STATIC RIKS by introducing geometric and material nonlinearity. A scale factor of 0.2 times the thickness of the section [15] was adopted to introduce imperfection in the first buckling mode by using the keyword *IMPERFECTION from ABAQUS library. A typical first buckling mode for column $\mathrm{Cl}$ of effective length $600 \mathrm{~mm}$ is shown in Figure 2.

2.2. Material Modelling. The material assigned was considered as isotropic and homogenous. In ABAQUS, while defining the material property, the nominal stress and strain values were converted to true stress and logarithmic plastic strain using the following:

$$
\begin{gathered}
\sigma_{\text {true }}=\sigma_{\text {nom }}\left(1+\varepsilon_{\text {nom }}\right), \\
\varepsilon^{\mathrm{pl}}=\ln \left(1+\varepsilon_{\text {nom }}\right)-\frac{\sigma_{\text {true }}}{E} .
\end{gathered}
$$

In the present study, the stress-strain plot was considered as bilinear. The following material properties were adopted for a thickness of $2 \mathrm{~mm}$ :

$$
\begin{aligned}
& \text { Young's modulus, } E=209 \mathrm{GPa} \text {, } \\
& \text { Poisson's ratio, } \mu=0.3 \text {, } \\
& \text { yield stress, } f_{y}=450 \mathrm{MPa} \text {, } \\
& \text { ultimate stress, } f_{u}=550 \mathrm{MPa} \text {, } \\
& \text { strain corresponding to ultimate stress, } \varepsilon=10 \% \text {. }
\end{aligned}
$$

2.3. Element Type Meshing and Assembly. The channels were modelled using shell element. S4R5 element type was chosen. S4R5 is a 4-node doubly curved thin shell element, reduced integration, hourglass control, using 5 degrees of freedom per node. The end plates were modelled with 3D4 elements, that is, a 4 -node $3 \mathrm{D}$ rigid quadrilateral element. A mesh convergence study was made and a suitable mesh size of $5 \mathrm{~mm}$ $\times 5 \mathrm{~mm}$ was chosen.

The rigid plates were assembled such that their centroids either coincide with the centroid of the cross-section or move away from it so that axially loaded and eccentrically loaded conditions are achieved, respectively. A typical column for both of the cases is shown in Figures 3 and 4, respectively.

2.4. Contact Pair Definition. A contact pair was defined between the rigid plates and the channel section edges for the transfer of load. A node to surface contact was defined in both tangential and normal directions. Hard contact was defined in the normal direction to ensure that there is no penetration of the edges and plate. A friction ratio was defined in the tangential direction to prevent sliding between plates and the column.

2.5. Loading and Boundary Conditions. The columns were analysed for pinned-pinned boundary conditions, which was achieved by restraining all the translational degrees of freedom at both of the edges of channel sections except the translational degree of freedom in the axial direction at the top end. Force controlled loading was adopted by applying pressure load on the top plate. The corresponding details are shown in Figure 5. 


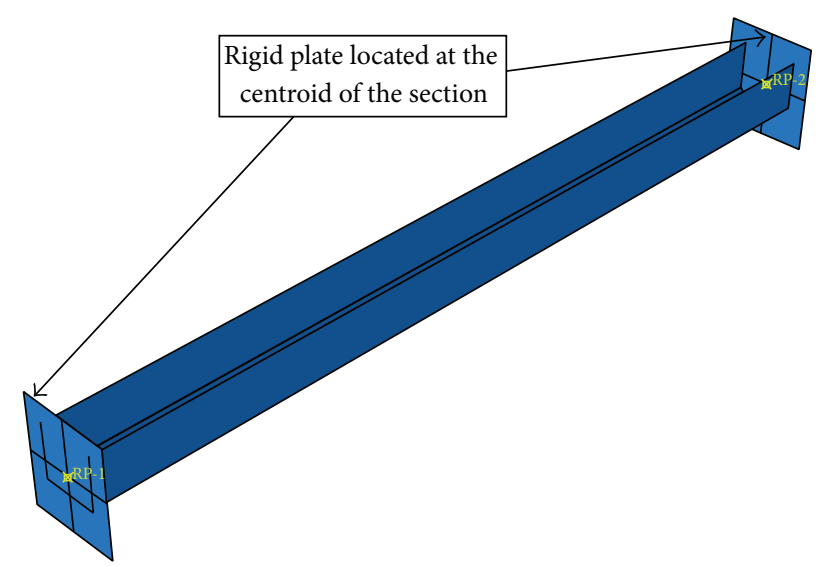

Figure 3: Axially loaded column.

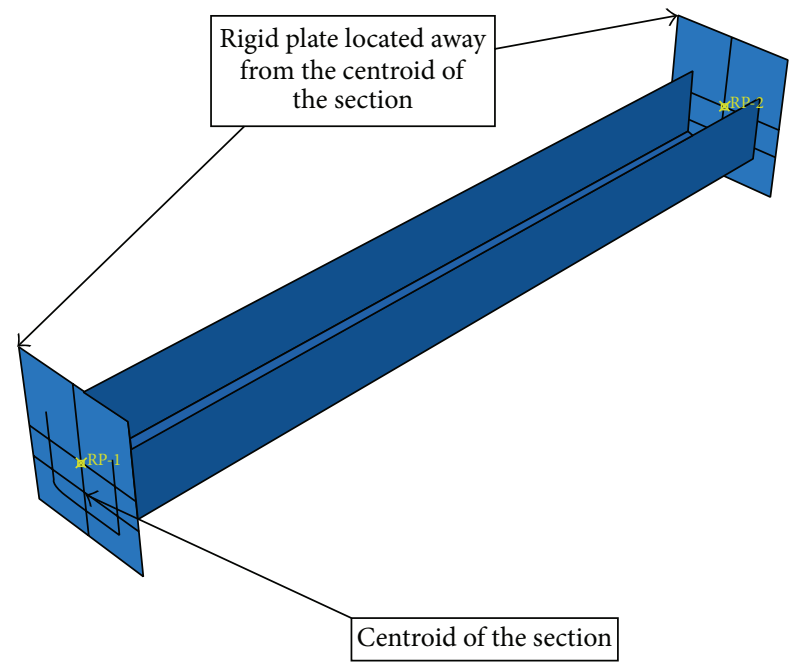

FIgURE 4: Eccentrically loaded column.

2.6. Validation. Nonlinear finite element model was developed for a plain channel section by using the input from Young and Yan [6].

A series of fixed ended plain cold-formed channel sections were modelled and analysed. Since the finite element model was overestimating the experimental values, which could be probably due to the small values of residual stresses and the rounded corners of the sections that were ignored in the FEM, a column strength equation was proposed as a function of the effective length and the ultimate load from finite element modelling as in the following:

$$
P_{\mathrm{FEA}}^{*}=(0.95-0.02 L) P_{\mathrm{FEA}},
$$

where $L=$ effective length in $\mathrm{m}$.

The comparison of the current study and the available results is shown in Figure 6.
2.7. Nonuniform Compression Factor, $\alpha$. A nonuniform compression factor was defined in terms of the stresses at the edges of the unstiffened element as follows:

$$
\alpha=1-\frac{\sigma_{\min }}{\sigma_{\max }} .
$$

Two cases were considered: maximum compression at free edge $(F)$ and maximum compression at supported edge $(S)$. The unsupported edge of the unstiffened element is taken as the free edge and the other edge which is supported by the stiffened element is taken as the supported edge. Three values were considered for $\alpha(0,0.5$, and 1$)$. The description for these values is given in Table 2. The positions of load for various values of $\alpha$ are shown in Figures 7(a), 7(b), and 7(c).

\section{CUFSM and Direct Strength Method}

3.1. General. The two important methods available for the design of cold-formed members are the effective width method (EWM) and the direct strength method (DSM). The results obtained from finite element modelling for axially loaded columns were compared with DSM results.

3.2. Direct Strength Method. The direct strength method is a new design method which was adopted in 2004 as Appendix 1 to the North American Specification for the Design of Cold-Formed Steel Structural Members. The most important advantages of using DSM are the following: (1) effective widths need not be calculated, (2) gross properties of the sections are used, (3) iterations for the determination of member design strength are not required, and (4) interaction of elements in local buckling is considered. In DSM, the elastic buckling loads in local, distortional, and global buckling and that which causes first yield are determined and employed in a series of equations to directly provide the strength prediction. DSM is extensively developed for beams and columns only.

The nominal axial strength $P_{n}$ is the minimum of $P_{\mathrm{ne}}, P_{\mathrm{nl}}$, and $P_{\text {nd }}$ as given below. These equations are applicable for columns subjected to pure compression only.

3.2.1. Flexural, Torsional, or Flexural-Torsional Buckling. The nominal axial strength $P_{\text {ne }}$, for flexural, torsional, or flexuraltorsional buckling, is shown as follows:

$$
\begin{gathered}
P_{\mathrm{ne}}=\left(0.658 \lambda_{c}^{2}\right) P_{y} \quad \text { for } \lambda_{c} \leq 1.5 \\
P_{\mathrm{ne}}=\left(\frac{0.877}{\lambda_{c}^{2}}\right) P_{y} \quad \text { for } \lambda_{c}>1.5, \\
\text { where } \lambda_{c}=\sqrt{\frac{P_{\mathrm{cr}}}{P_{y}}} \\
P_{y}=A_{g} F_{y} .
\end{gathered}
$$




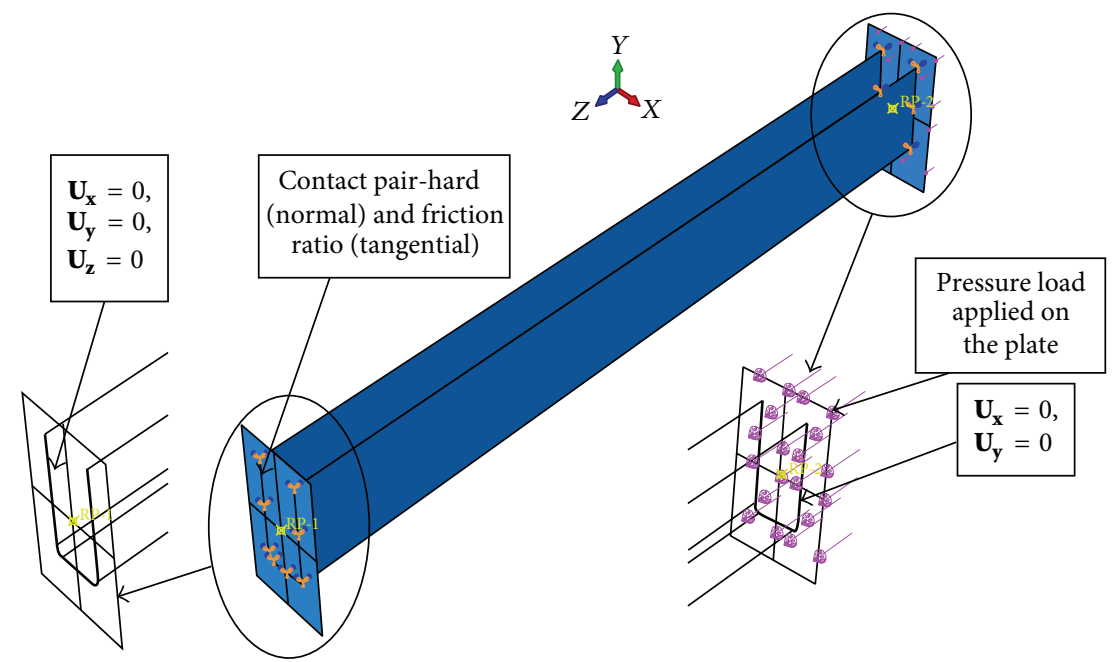

FIGURE 5: Details of the model.

3.2.2. Local Buckling. The nominal axial strength $P_{\mathrm{nl}}$, for local buckling, is shown as follows:

$$
\begin{gathered}
P_{\mathrm{nl}}=P_{\mathrm{ne}} \text { for } \lambda_{\mathrm{l}} \leq 0.776 \\
P_{\mathrm{nl}}=P_{\mathrm{ne}}\left[1-0.15\left(\frac{P_{\mathrm{crl}}}{P_{\mathrm{ne}}}\right)^{0.4}\right]\left(\frac{P_{\mathrm{crl}}}{P_{\mathrm{ne}}}\right)^{0.4} \text { for } \lambda_{\mathrm{l}}>0.776 \\
\text { where } \lambda_{\mathrm{l}}=\sqrt{\frac{P_{\mathrm{ne}}}{P_{\mathrm{crl}}}}
\end{gathered}
$$

3.2.3. Distortional Buckling. The nominal axial strength $P_{\mathrm{nd}}$, for distortional buckling, is shown as follows:

$$
\begin{gathered}
P_{\mathrm{nd}}=P_{y} \quad \text { for } \lambda_{d} \leq 0.561 \\
P_{\mathrm{nd}}=P_{y}\left[1-0.25\left(\frac{P_{\mathrm{crd}}}{P_{y}}\right)^{0.6}\right]\left(\frac{P_{\mathrm{crd}}}{P_{y}}\right)^{0.6} \text { for } \lambda_{\mathrm{d}}>0.561 \\
\text { where } \lambda_{d}=\sqrt{\frac{P_{y}}{P_{\mathrm{crd}}}}
\end{gathered}
$$

3.3. CUFSM. CUFSM is a software program which is freely available for exploring elastic buckling behaviour of thin-walled members. It helps in calculating the buckling stress and buckling modes of various sections. Initially, it was developed only for simply supported conditions. Later, it was developed for other boundary conditions such as clamped-clamped, simple-clamped, clamped-free, and clamped-guided. The following points help in better understanding the necessity of using CUFSM.

(1) Design and hand methods that are traditionally used for plate structures often ignore the compatibility at
TABLE 2: Nonuniform compression factor.

\begin{tabular}{lc}
\hline$\alpha$ & Description \\
\hline 0 & Uniform compression \\
0.5 & $\sigma_{\min }=0.5 * \sigma_{\max }$ \\
1 & $\sigma_{\min }=0$ \\
\hline
\end{tabular}

plate junctures and typically provide no means to calculate a variety of buckling modes.

(2) CUFSM allows all elastic buckling modes of a structure to be quantified and examined.

(3) In order to calculate input for DSM (say $P_{\text {cre }}, P_{\text {crl }}$, and $P_{\text {crd }}$ for compression members), CUFSM can be used instead of cumbersome hand calculations, thereby saving time.

3.4. Application of CUFSM and DSM for Plain Channel Columns. In plain channel columns, there is no distortional buckling due to the absence of edge or intermediate stiffeners. Hence, in CUFSM, the plain channels sections were modelled and analysed for simply supported conditions, and load factor was obtained for global and local buckling modes. The load factor is the ratio of elastic buckling load to the first yield load from which $P_{\text {cr }}$ was determined for each of the two buckling modes. These values were then employed in (4) to (5). The minimum of the nominal strengths in global and local buckling modes was taken as the nominal axial strength of the column subjected to pure compression.

\section{Results and Discussion}

4.1. Influence of Effective Length. Each of the columns was analysed for four effective lengths (300, 600, 900, and $1200 \mathrm{~mm}$ ). The elastic buckling loads and ultimate loads are tabulated in Table 3 for axially loaded condition. 
TABLE 3: Influence of effective length on axially loaded columns C1 to C4.

\begin{tabular}{|c|c|c|c|c|c|c|c|c|}
\hline \multirow{2}{*}{ Column number } & \multirow{2}{*}{$L_{e}(\mathrm{~mm})$} & \multirow{2}{*}{$L_{e} / r_{\min }$} & \multicolumn{3}{|c|}{ Elastic buckling load, $P_{\mathrm{cr}}(\mathrm{kN})$} & \multicolumn{3}{|c|}{ Ultimate load, $P_{u}(\mathrm{kN})$} \\
\hline & & & ABAQUS & CUFSM & ABAQUS/CUFSM & ABAQUS & DSM & ABAQUS/DSM \\
\hline \multirow{4}{*}{$\mathrm{C} 1$} & 300 & 13.48 & 36.53 & 35.00 & 1.04 & 52.46 & 84.63 & 0.62 \\
\hline & 600 & 26.96 & 34.54 & 33.04 & 1.05 & 50.05 & 63.84 & 0.78 \\
\hline & 900 & 40.44 & 34.35 & 33.11 & 1.04 & 48.81 & 42.52 & 1.15 \\
\hline & 1200 & 53.92 & 34.27 & 33.04 & 1.04 & 48.54 & 30.00 & 1.62 \\
\hline \multirow{4}{*}{$\mathrm{C} 2$} & 300 & 11.69 & 21.04 & 20.31 & 1.04 & 38.73 & 75.00 & 0.52 \\
\hline & 600 & 23.38 & 20.13 & 19.67 & 1.02 & 28.36 & 60.33 & 0.47 \\
\hline & 900 & 35.06 & 19.69 & 19.19 & 1.03 & 32.86 & 42.62 & 0.77 \\
\hline & 1200 & 46.75 & 19.64 & 19.16 & 1.03 & 33.36 & 29.85 & 1.12 \\
\hline \multirow{4}{*}{$\mathrm{C} 3$} & 300 & 11.60 & 43.92 & 41.95 & 1.05 & 54.25 & 70.62 & 0.77 \\
\hline & 600 & 23.20 & 42.86 & 41.62 & 1.03 & 49.73 & 58.95 & 0.84 \\
\hline & 900 & 34.80 & 42.45 & 41.33 & 1.03 & 49.12 & 44.66 & 1.10 \\
\hline & 1200 & 46.40 & 42.24 & 41.32 & 1.02 & 45.83 & 32.33 & 1.42 \\
\hline \multirow{4}{*}{ C4 } & 300 & 12.30 & 22.69 & 22.34 & 1.02 & 55.19 & 107.9 & 0.51 \\
\hline & 600 & 24.60 & 22.78 & 22.34 & 1.02 & 43.41 & 84.59 & 0.51 \\
\hline & 900 & 36.90 & 22.78 & 22.34 & 1.02 & 41.10 & 56.91 & 0.72 \\
\hline & 1200 & 49.20 & 22.72 & 22.34 & 1.02 & 40.19 & 39.82 & 1.01 \\
\hline
\end{tabular}

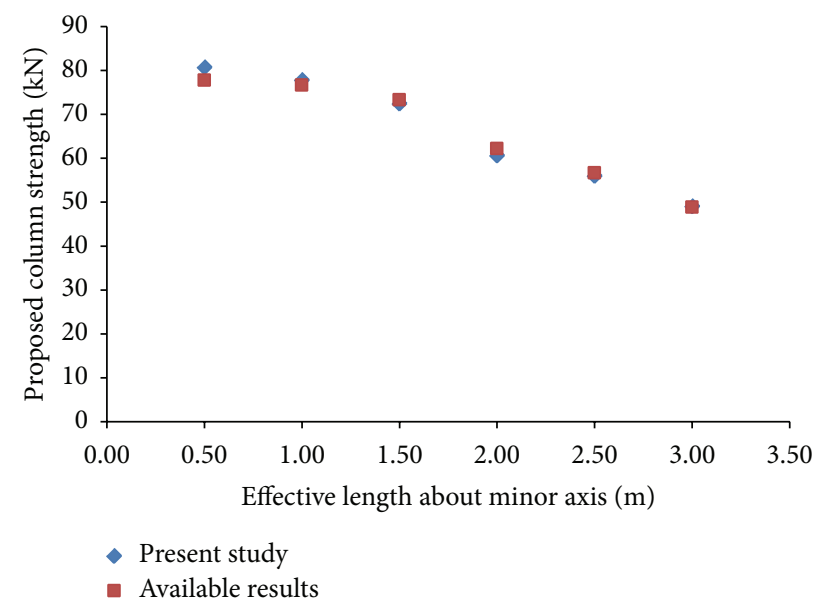

Figure 6: Validation.

It could be seen that the elastic buckling loads obtained from ABAQUS were higher than those from CUFSM. A maximum variation of $4.3 \%$ was evident. On average, the variation lies in the range of $1.8 \%$ to $4 \%$. The variation in results is mainly because rounded corners are not modelled in CUFSM. Also, the mesh size in both of the software programs plays an important role.

Though the elastic buckling loads from ABAQUS and CUFSM were nearly the same for almost all cases, for columns of higher $b_{f} / t$ ratios, the results are in better agreement and the elastic buckling load was constant as the effective length increased. Based on the similarities in elastic buckling loads from ABAQUS and CUFSM, it was concluded that the modelling parameters adopted in ABAQUS are in
TABLE 4: Influence of $b_{f} / t$ ratio for axially loaded columns.

\begin{tabular}{lcccc}
\hline Column number & $b_{f} / t$ & FEM (kN) & DSM (kN) & FEM/DSM \\
\hline C2-BF-34.60 & 15.53 & 62.07 & 57.19 & 1.09 \\
C2-BF-56.80 & 28.36 & 50.22 & 60.33 & 0.83 \\
C2-BF-69.20 & 35.53 & 47.68 & 61.70 & 0.77 \\
C2-BF-86.50 & 45.53 & 42.07 & 62.93 & 0.67 \\
C2-BF-103.80 & 55.53 & 37.77 & 64.95 & 0.58 \\
C2-BF-121.10 & 65.53 & 35.10 & 65.54 & 0.54 \\
C2-BF-138.40 & 75.53 & 32.48 & 66.88 & 0.49 \\
\hline
\end{tabular}

good correlation and could be used for other parametric studies as well.

With regard to ultimate load, the results from ABAQUS and DSM were equivalent for only one length for all the four columns. Load displacement plots obtained for an effective length of $600 \mathrm{~mm}$ are shown in Figure 8. The results converged better for all lengths of column C3 (lower $b_{f} / t$ ratio) compared to other columns.

4.2. Influence of $b_{f} / t$ Ratio. The width of the unstiffened element was alone varied in column $\mathrm{C} 2$, for an effective length of $500 \mathrm{~mm}$ with other parameters maintained constant. The column name "C2-BF-34.60" represents column C2 having width of the unstiffened element changed to $34.60 \mathrm{~mm}$. The columns were analysed under axially loaded condition. The ultimate loads obtained from ABAQUS were compared with DSM results. The results are given in Table 4 . The results converged better for columns with lower $b_{f} / t$ ratios.

4.3. Influence of Nonuniform Compression Factor. All the columns of different lengths were analysed in ABAQUS for 


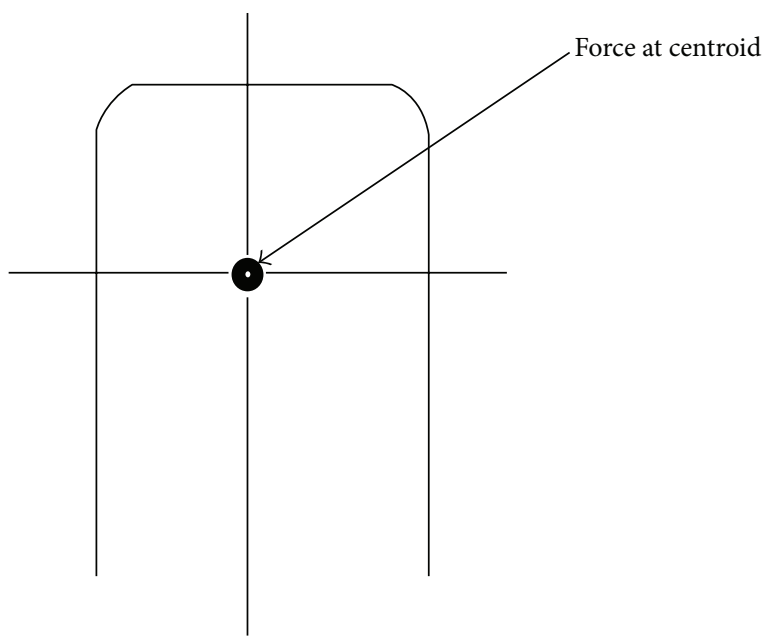

(a)

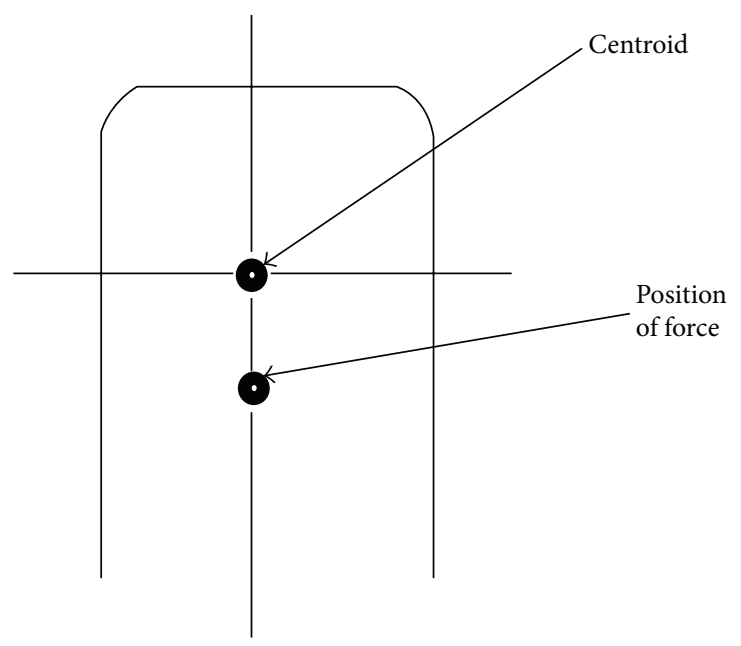

(b)

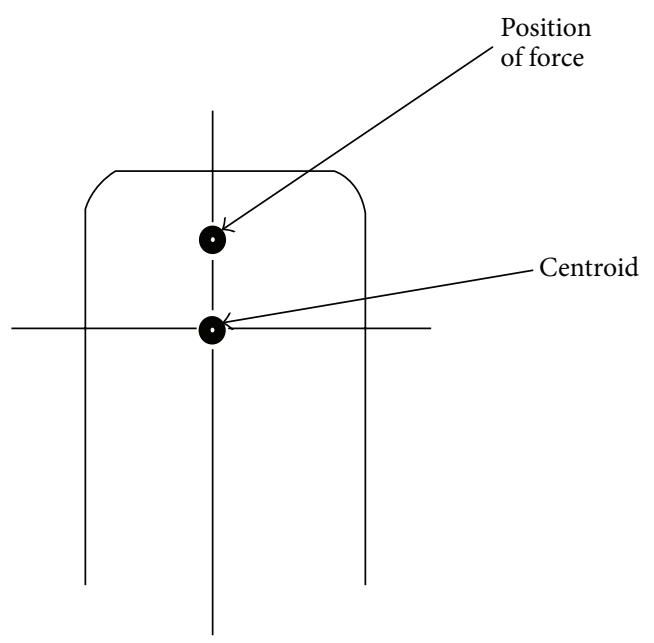

(c)

FIGURE 7: Position of force for (a) $\alpha=0$, (b) maximum compression at free edge, and (c) maximum compression at supported edge.

three values of nonuniform compression factor $(0,0.5$, and 1) considering both of the cases of maximum compression at free edge and supported edge.

The ultimate load was higher for the case of maximum compression at supported edge than at free edge. Considering the case of maximum compression at free edge, the ultimate load and elastic buckling load decreased as the slenderness ratio increased, for any value of $\alpha$, and decreased as $\alpha$ increased, for any effective length. The variation of $P_{\mathrm{cr}}$ and $P_{u}$ with respect to $\alpha$ for the case of maximum compression at free edge of column $\mathrm{C} 1$ is shown in Figure 9.

Under the case of maximum compression at supported edge, the ultimate load increased as $\alpha$ increased but there was a steep increase of ultimate load when $\alpha$ increased from 0.5 to 1 for columns of higher $b_{f} / t$ ratio. The load displacement plots for columns $\mathrm{C} 1$ and $\mathrm{C} 3$ for all $\alpha$ values for both of the cases are shown in Figures 10 and 11, respectively ( $F$ : maximum compression at free edge, $S$ : maximum compression at supported edge).
It was observed that the aspect ratio of the unstiffened element had a significant influence on the variation of elastic buckling loads with respect to $\alpha$, when there was maximum compression at the supported edge. The variation of elastic buckling loads with respect to $\alpha$ is presented in Figure 12.

4.4. Influence of Aspect Ratio (Effective Length/Flat Width) of Unstiffened Element. In column C3, the width of the unstiffened element alone was varied such that the widthto-thickness ratio ranges from 30 to 80 , with an effective length of $300 \mathrm{~mm}$. The columns were analysed in ABAQUS for all three nonuniform compression factors under the case of maximum compression at supported edge. The influence of $\alpha$ on the elastic buckling loads reduced and the ultimate loads increased drastically when $\alpha$ increased from 0.5 to 1 , for an aspect ratio of unstiffened elements in the range of 2.5 to 4.5 . The corresponding plots are shown in Figures 13 and 14 , respectively. 


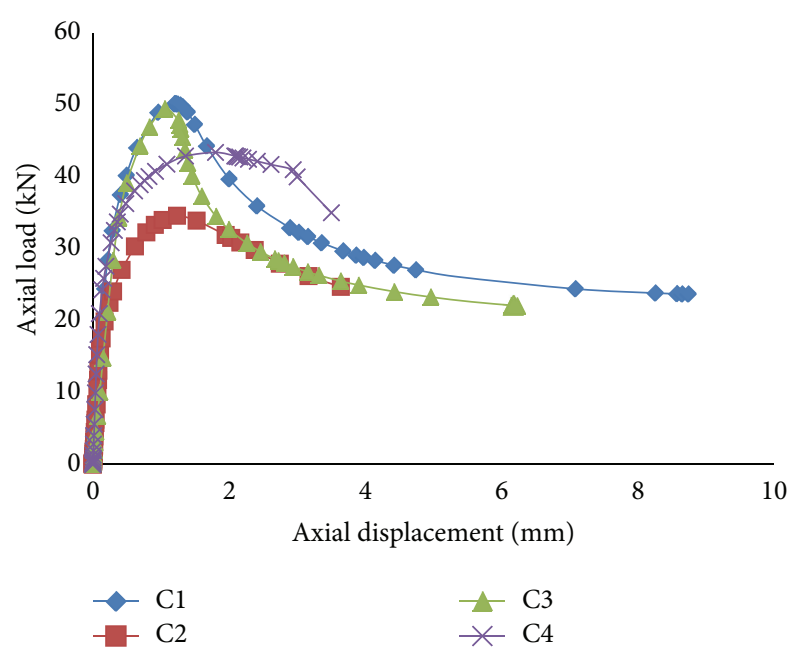

FIGURE 8: Load displacement plots for axially loaded columns $\mathrm{C} 1$ to C4 for an effective length of $600 \mathrm{~mm}$.

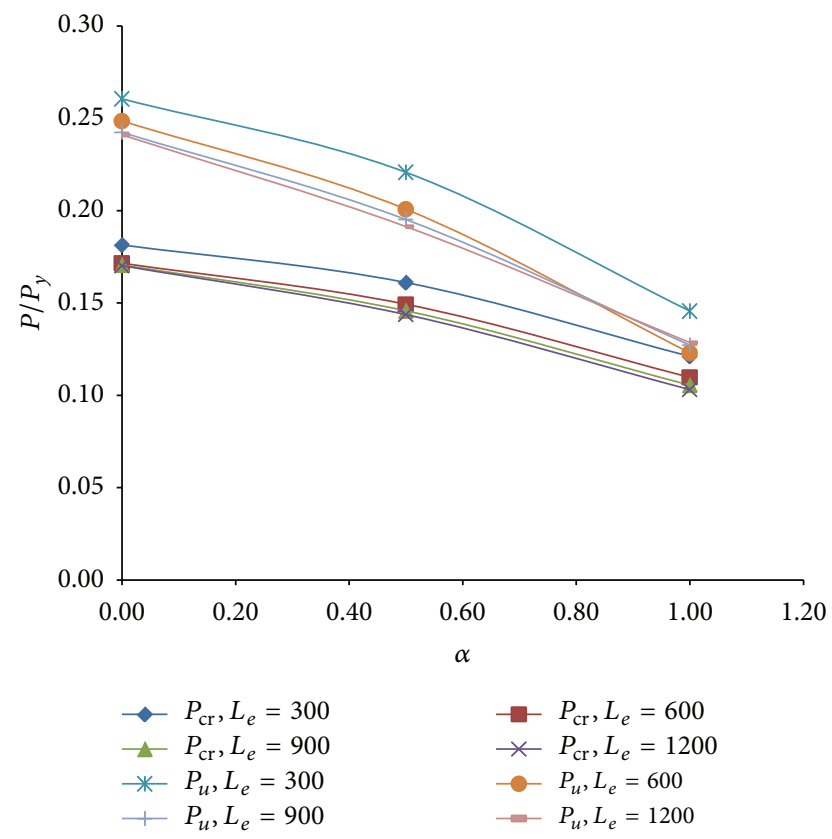

FIgURE 9: $P_{\mathrm{cr}}$ and $P_{u}$ versus $\alpha$ for the case of maximum compression at free edge of column $\mathrm{Cl}$.

\section{Conclusion}

The following conclusions were made based on the works done. When the columns were loaded axially, the results from ABAQUS show that the ultimate loads obtained from direct strength method are equivalent only for a certain range of slenderness ratio (35 to 50). When the columns were loaded eccentrically, only the sensitivity of the elastic buckling load and ultimate load with respect to nonuniform compression factor was studied. In general, it was seen that the ultimate loads were higher when the position of load moved towards the supported edge. In most of the open sections, shear centre does not coincide with the centroid due to which it lies away

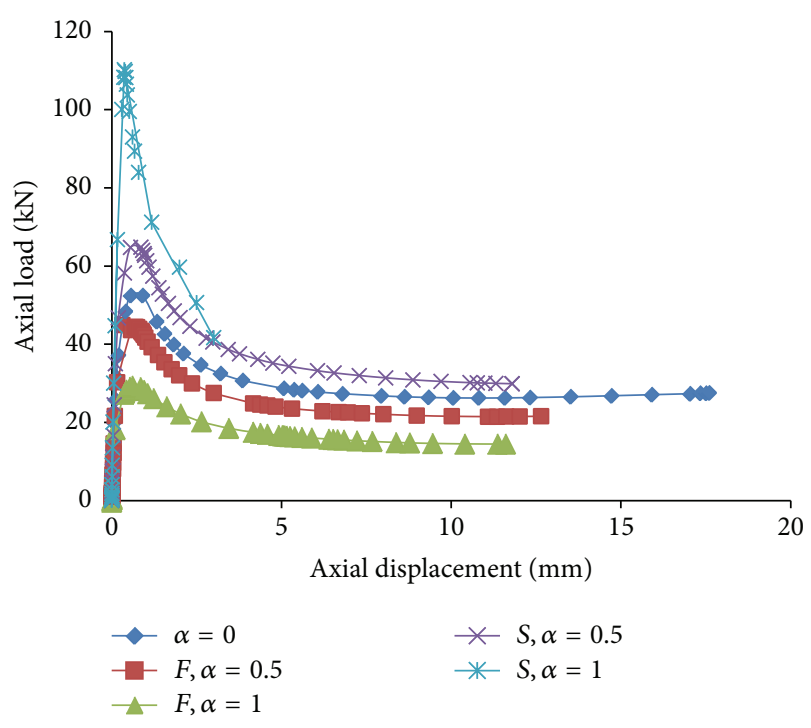

FIGURE 10: Load displacement plots for column C1 for all values of $\alpha\left(L_{e}=300 \mathrm{~mm}\right)$.

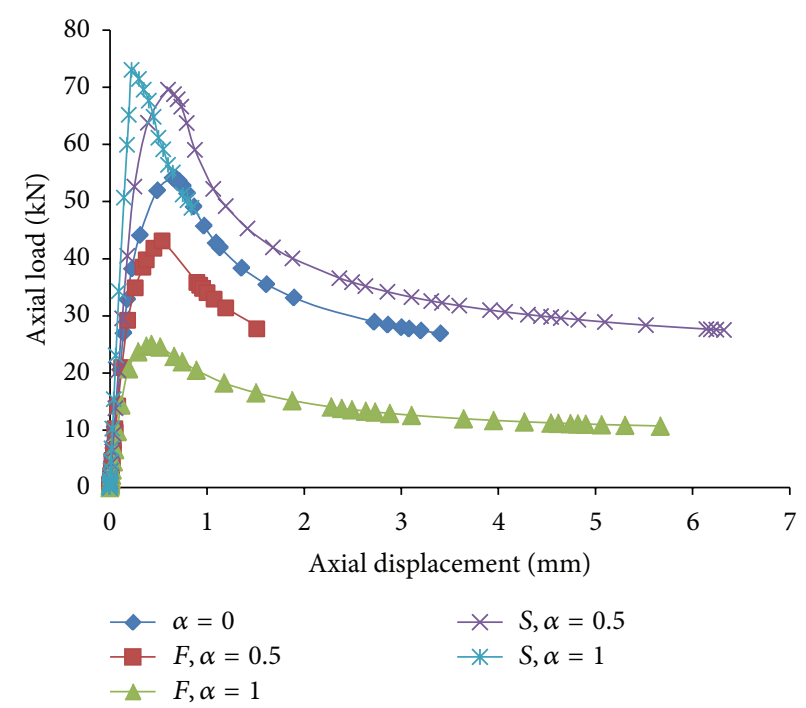

FIGURE 11: Load displacement plots for column C3 for all values of $\alpha\left(L_{e}=300 \mathrm{~mm}\right)$.

from the centroid outside the stiffened element. This could be one of the reasons for higher ultimate loads when there is maximum compression at the supported edge thereby getting torsional buckling reduced. Another main reason could be that when there is maximum compression at the supported edge, the axial compression on the flanges gets reduced which in turn prevents premature flange buckling. The study on the aspect ratio of the unstiffened elements, when the columns were loaded such that the maximum compression would be at the supported edge of the unstiffened element, showed that the elastic buckling loads were least affected by the load eccentricity for a certain range of $L_{e} / b_{f}$ and that the increase in ultimate loads for $\alpha=0.5$ to $\alpha=1$ was also a function of $L_{e} / b_{f}$. 


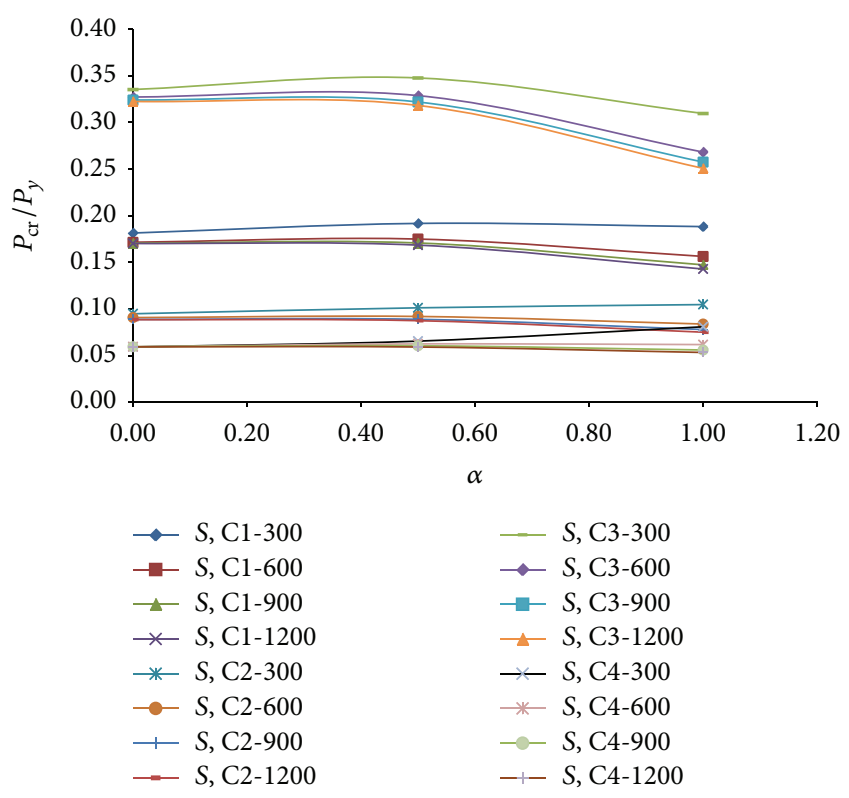

Figure 12: Variation of elastic buckling load with respect to nonuniform compression factor for all the columns (maximum compression at supported edge).

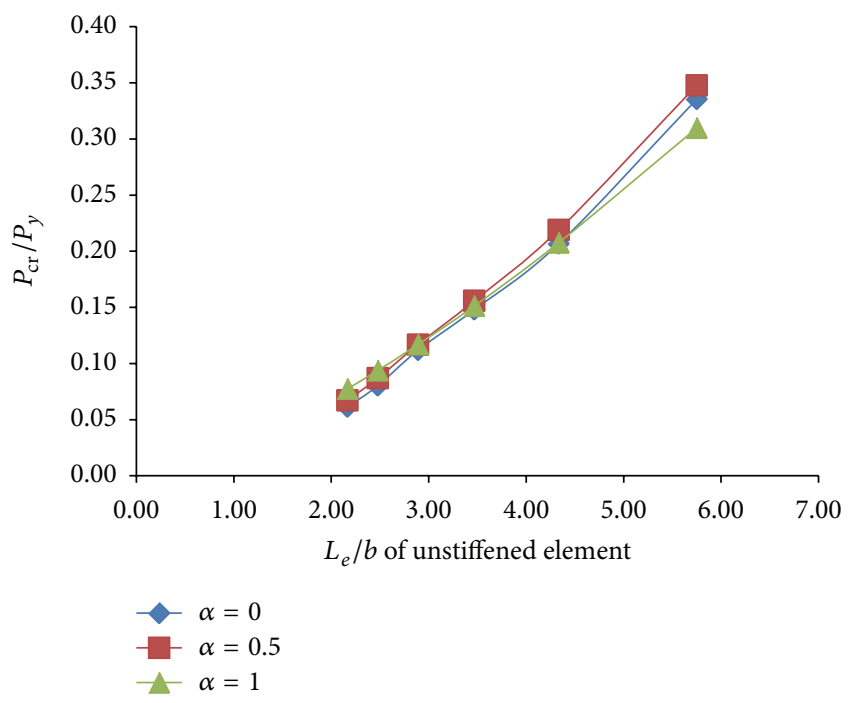

FIGURE 13: Influence of the aspect ratio of the unstiffened element on the elastic buckling load when maximum compression is at supported edge.

\section{Nomenclature}

$A_{g}:$ Gross area of the section

$B_{f}$ : Width of the unstiffened element (flange)

$B_{w}$ : Width of the stiffened element (web)

$b_{f}$ : Flat width of unstiffened element (flange)

$b_{w}: \quad$ Flat width of stiffened element (web)

$t$ : Thickness of the section

$R: \quad$ Inner radius of the section

$\sigma_{\min }:$ Minimum stress at one edge of the unstiffened element

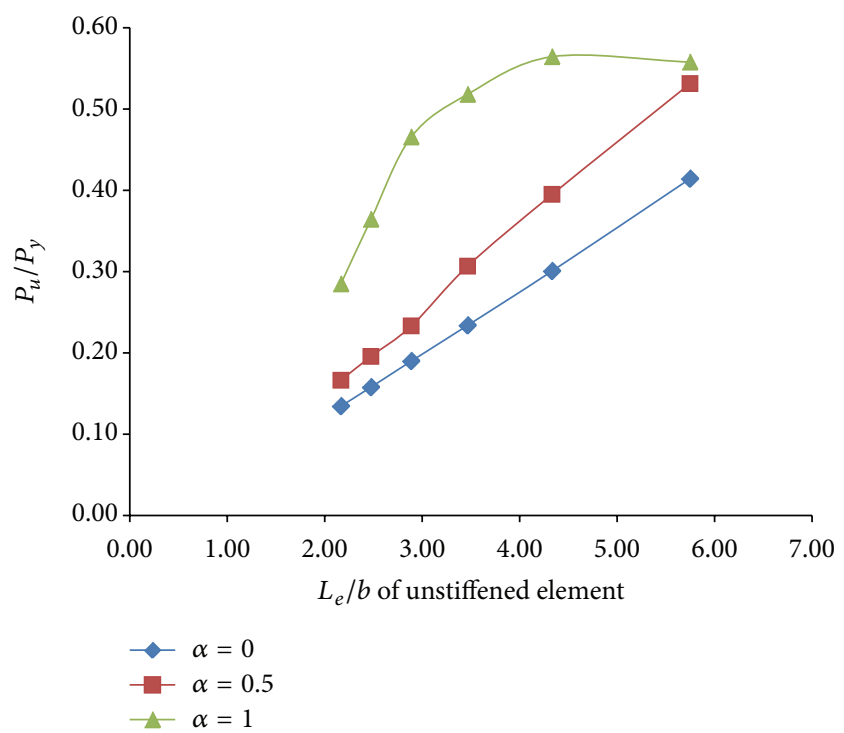

FIGURE 14: Influence of the aspect ratio of the unstiffened element on the ultimate load when maximum compression is at supported edge.

$\sigma_{\max }:$ Maximum stress at the other edge of the unstiffened element

$\sigma_{\text {true }}:$ True stress

$\sigma_{\text {nom }}:$ Nominal stress

$\varepsilon_{\text {nom }}:$ Nominal strain

$\varepsilon^{\mathrm{pl}}: \quad$ Logarithmic plastic strain

$\alpha: \quad$ Nonuniform compression factor

$\mu$ : Poisson's ratio

E: Young's modulus

$f_{y}: \quad$ Yield stress

$f_{u}$ : Ultimate stress

$P_{\mathrm{cr}}: \quad$ Elastic buckling load

$P_{y}: \quad$ First yield load

$P_{u}: \quad$ Ultimate load

$P_{\text {crl }}:$ Critical elastic local column buckling load

$P_{\text {cre }}$ : Minimum of the critical elastic column buckling load in flexural, torsional, or flexural-torsional buckling

$P_{\text {crd }}:$ Critical elastic distortional column buckling load

$P_{\text {ne }}: \quad$ Nominal axial strength for flexural, torsional, or flexural-torsional buckling

$P_{\mathrm{nl}}: \quad$ Nominal axial strength for local buckling

$P_{\text {nd }}$ : Nominal axial strength for distortional buckling

$P_{n}: \quad$ Nominal axial strength of the column

$P_{\mathrm{FEA}}^{*}$ : Proposed column strength

$P_{\mathrm{FEA}}$ : Ultimate load obtained from ABAQUS

$L_{e}: \quad$ Effective length of the column

$r_{\min }$ : Minimum radius of gyration.

\section{Conflict of Interests}

The authors declare that there is no conflict of interests regarding the publication of this paper. 


\section{References}

[1] V. Kalyanaraman and P. Ramakrishna, "Non-uniformly compressed stiffened elements," in Proceedings of the 7th International Specialty Conference on Cold-Formed Steel Structures, St. Louis, Mo, USA, 1984.

[2] V. Kalyanaraman and P. Jayabalan, "Local buckling of stiffened and unstiffened elements under nonuniform compression," in Proceedings of the 12th International Specialty Conference on Cold-Formed Steel Structures: Recent Research and Developments in Cold-Formed Steel Design and Construction, pp. 1-9, St. Loutis, Mo, USA, October 1994.

[3] A. I. El-Sheikh, E. M. A. El-Kassas, and R. I. Mackie, "Performance of stiffened and unstiffened cold-formed channel members in axial compression," Engineering Structures, vol. 23, no. 10, pp. 1221-1231, 2001.

[4] B. W. Schafer, Z. Li, and C. D. Moen, "Computational modeling of cold-formed steel," Thin-Walled Structures, vol. 48, no. 10-11, pp. 752-762, 2010.

[5] B. Young and J. Yan, "Channel columns undergoing local, distortional, and overall buckling," Journal of Structural Engineering, vol. 128, no. 6, pp. 728-736, 2002.

[6] B. Young and J. Yan, "Finite element analysis and design of fixedended plain channel columns," Finite Elements in Analysis and Design, vol. 38, no. 6, pp. 549-566, 2002.

[7] B. Young and K. J. R. Rasmussen, "Behaviour of cold-formed singly symmetric columns," Thin-Walled Structures, vol. 33, no. 2, pp. 83-102, 1999.

[8] H. T. Nguyen and S. E. Kim, "Buckling of composite columns of lipped-channel and hat sections with web stiffener," Thin-Walled Structures, vol. 47, no. 11, pp. 1149-1160, 2009.

[9] C. G. Wang, Z. F. Xu, Z. N. Zhang, and Y. F. Cao, "Load-carrying capacity of cold-formed steel columns with complicated section under eccentric compression loading," Advanced Materials Research, vol. 838-841, pp. 601-604, 2013.

[10] T. H. Miller and T. Pekoz, "Load-eccentricity effects on coldformed steel lipped-channel columns," Journal of Structural Engineering, vol. 120, no. 3, pp. 805-823, 1994.

[11] J. Rhodes, M. Macdonald, and W. McNiff, "Buckling of cold formed stainless steel columns under concentric and eccentric loading," in Proceedings of the 15th International Specialty Conference on Cold-Formed Steel Structures: Recent Research and Developments in Cold-Formed Steel Design and Construction, pp. 687-699, St. Louis, Mo, USA, October 2000.

[12] J. Dejin and C. Shaofan, "Inelastic torsional-flexural buckling of cold-formed open sections under eccentric load," in Proceedings of the 7th International Specialty Conference on Cold-Formed Steel Structures, St. Louis, Mo, USA, 1984.

[13] B. W. Schafer, "Review: The Direct Strength Method of coldformed steel member design," Journal of Constructional Steel Research, vol. 64, no. 7-8, pp. 766-778, 2008.

[14] B. W. Schafer and S. Adany, "Buckling analysis of cold-formed steel members using CUFSM: conventional and constrained finite strip methods," in Proceedings of the 18th International Specialty Conference on Cold-Formed Steel Structures: Recent Research and Developments in Cold-Formed Steel Design and Construction, pp. 39-54, October 2006.

[15] P. Jayabalan, Behaviour of non uniformly compressed thin unstiffened elements [Ph.D. thesis], Deptartment of Civil Engineering, India Institute of Technology Madras, 1989. 

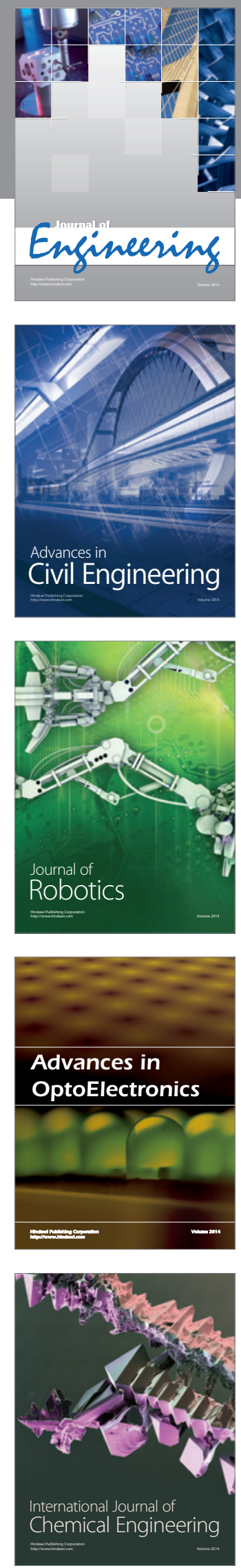

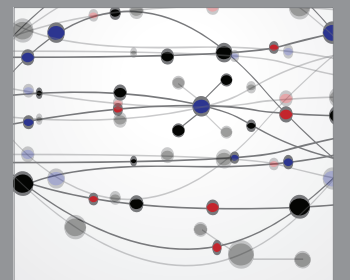

The Scientific World Journal
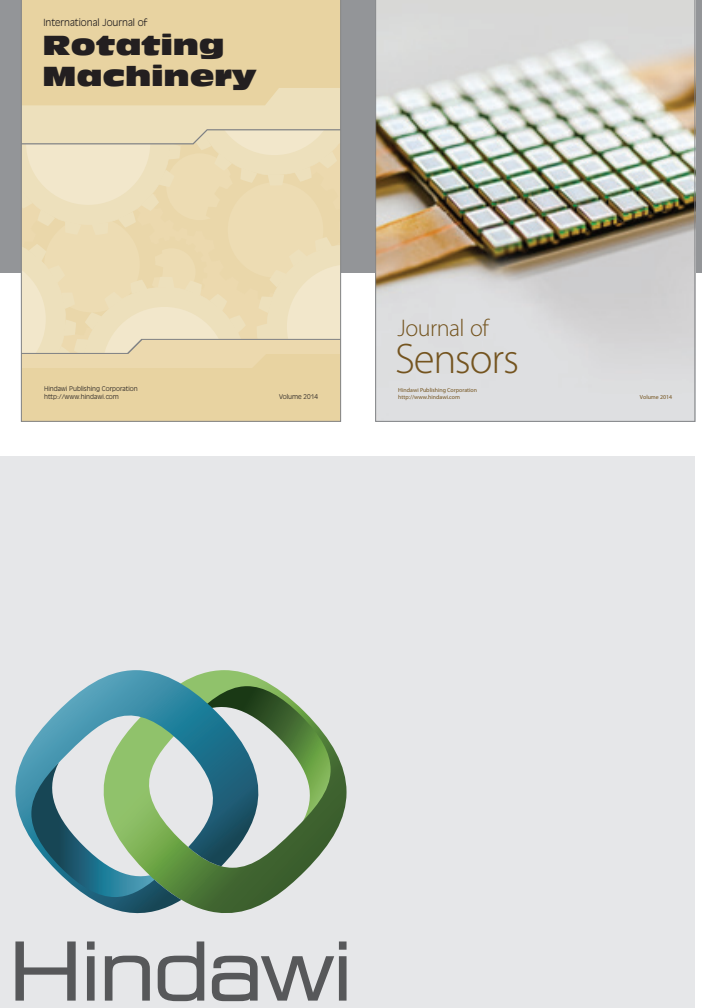

Submit your manuscripts at http://www.hindawi.com
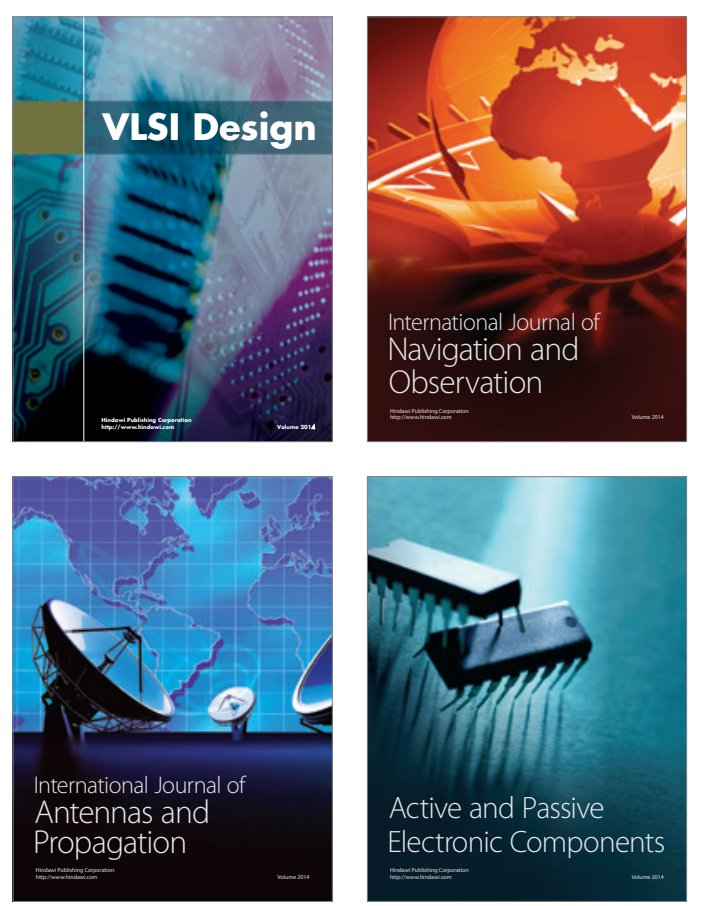
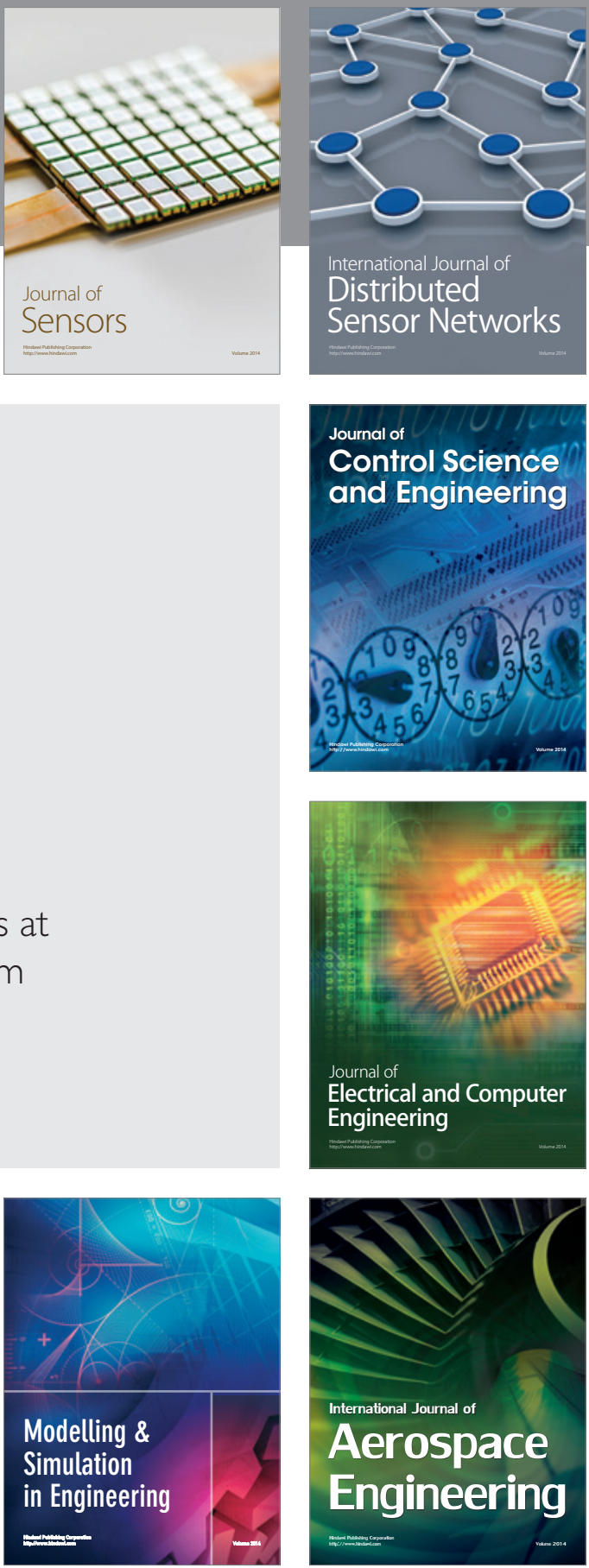

Journal of

Control Science

and Engineering
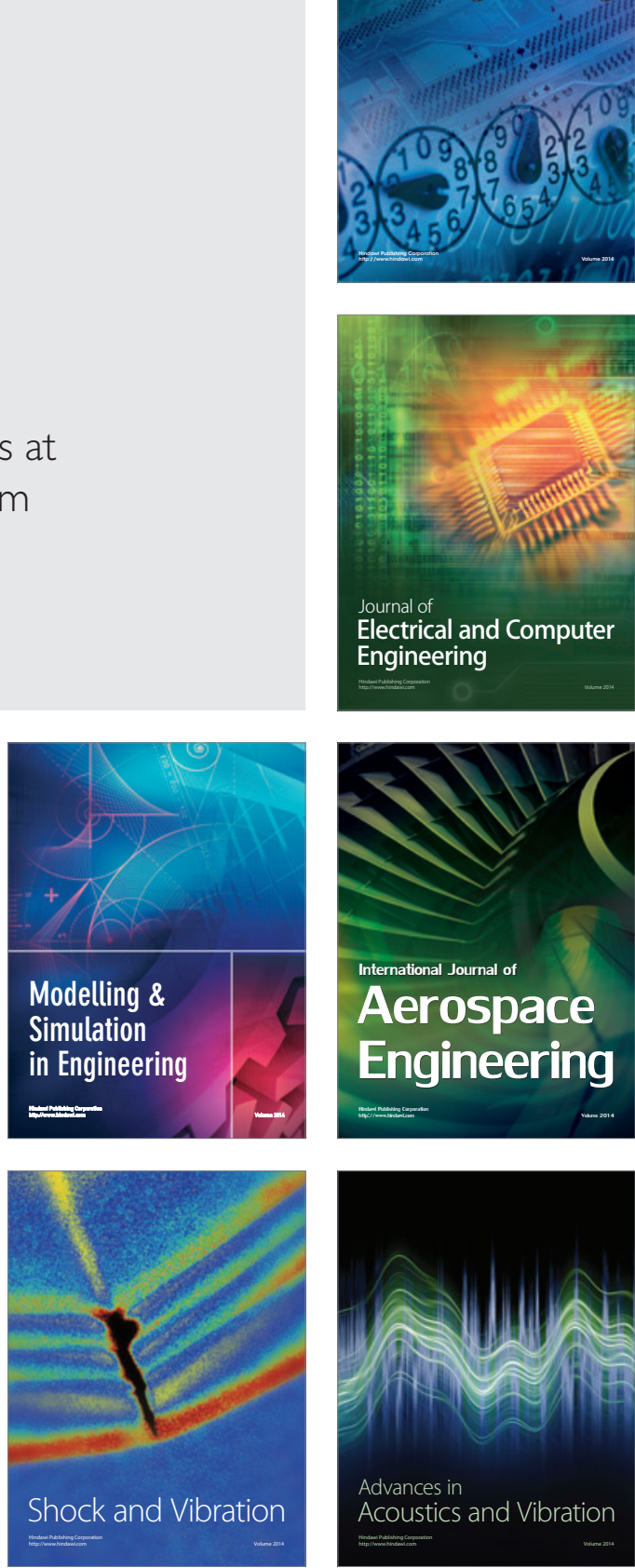